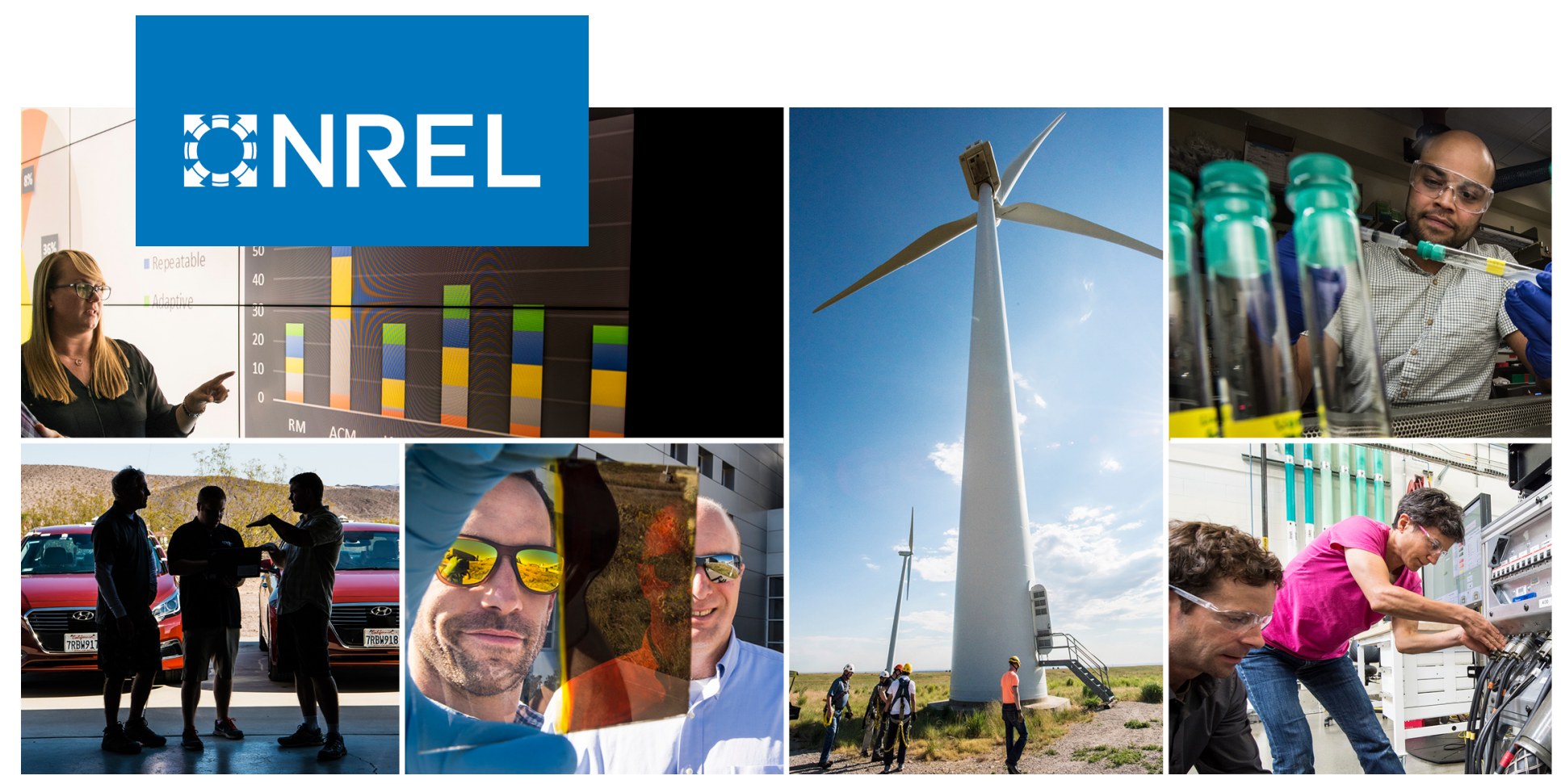

\title{
Investigating the Impact of Power-Take- Off System Parameters and Control Law on a Rotational Wave Energy Converter's Peak-To-Average Power Ratio Reduction
}

\section{Preprint}

H. Bora Karayaka, ${ }^{1}$ Yi-Hsiang $\mathrm{Yu},{ }^{2}$ Nathan Tom, ${ }^{2}$ and Eduard Muljadi ${ }^{3}$

1 Western Carolina University

2 National Renewable Energy Laboratory

3 Auburn University

Presented at the ASME 2020 39th International Conference on Ocean, Offshore and Arctic Engineering August 3-7, 2020

NREL is a national laboratory of the U.S. Department of Energy Office of Energy Efficiency \& Renewable Energy

Operated by the Alliance for Sustainable Energy, LLC

This report is available at no cost from the National Renewable Energy Laboratory (NREL) at www.nrel.gov/publications.
Conference Paper

NREL/CP-5000-76016

September 2020 


\title{
GHREL
}

\section{Investigating the Impact of Power-Take-} Off System Parameters and Control Law on a Rotational Wave Energy Converter's Peak-To-Average Power Ratio Reduction

\section{Preprint}

\author{
H. Bora Karayaka, ${ }^{1} \mathrm{Yi}-\mathrm{H}$ siang $\mathrm{Yu},{ }^{2}$ Nathan Tom, ${ }^{2}$ and \\ Eduard Muljadi ${ }^{3}$
}

1 Western Carolina University

2 National Renewable Energy Laboratory

3 Auburn University

\section{Suggested Citation}

Karayaka, H. Bora, Yi-Hsiang Yu, Nathan Tom, and Eduard Muljadi. 2020. Investigating the Impact of Power-Take-Off System Parameters and Control Law on a Rotational Wave Energy Converter's Peak-To-Average Power Ratio Reduction: Preprint. Golden, CO: National Renewable Energy Laboratory. NREL/CP-5000-76016.

https://www.nrel.gov/docs/fy20osti/76016.pdf.

NREL is a national laboratory of the U.S. Department of Energy Office of Energy Efficiency \& Renewable Energy Operated by the Alliance for Sustainable Energy, LLC

This report is available at no cost from the National Renewable Energy Laboratory (NREL) at www.nrel.gov/publications.

Contract No. DE-AC36-08GO28308
Conference Paper

NREL/CP-5000-76016

September 2020

National Renewable Energy Laboratory 15013 Denver West Parkway Golden, CO 80401

303-275-3000 • www.nrel.gov 


\section{NOTICE}

This work was authored in part by the National Renewable Energy Laboratory, operated by Alliance for Sustainable Energy, LLC, for the U.S. Department of Energy (DOE) under Contract No. DE-AC36-08GO28308. Funding provided by U.S. Department of Energy Office of Energy Efficiency and Renewable Energy Water Power Technologies Office. The views expressed herein do not necessarily represent the views of the DOE or the U.S. Government. The U.S. Government retains and the publisher, by accepting the article for publication, acknowledges that the U.S. Government retains a nonexclusive, paid-up, irrevocable, worldwide license to publish or reproduce the published form of this work, or allow others to do so, for U.S. Government purposes.

This report is available at no cost from the National Renewable Energy Laboratory (NREL) at www.nrel.gov/publications.

U.S. Department of Energy (DOE) reports produced after 1991 and a growing number of pre-1991 documents are available free via www.OSTI.gov.

Cover Photos by Dennis Schroeder: (clockwise, left to right) NREL 51934, NREL 45897, NREL 42160, NREL 45891, NREL 48097, NREL 46526.

NREL prints on paper that contains recycled content. 


\section{INVESTIGATING THE IMPACT OF POWER-TAKE-OFF SYSTEM PARAMETERS AND CONTROL LAW ON A ROTATIONAL WAVE ENERGY CONVERTER'S PEAK-TO-AVERAGE POWER RATIO REDUCTION}

\author{
H. Bora Karayaka ${ }^{1}$ \\ Western Carolina University \\ Cullowhee, NC, USA
}

\author{
Yi-Hsiang Yu, Nathan Tom \\ National Renewable Energy Laboratory \\ Golden, CO, USA
}

\author{
Eduard Muljadi \\ Auburn University \\ Auburn, AL, USA
}

\section{ABSTRACT}

Due to the irregular nature of real waves, the power captured in a wave energy converter (WEC) system is highly variable. This is an important barrier to the effective use of WECs. To address this challenge, this study focuses on a rotational WEC power-take-off system in which high-speed and high-efficiency generators along with a torque/power smoothing inertia element can be effectively utilized. In the first phase of this study, the U.S. Department of Energy's reference model 3 (WEC-Sim RM3; two-body point absorber), along with a slider-crank WEC, were integrated for linear to rotational conversion. Relative motion between the float and spar in RM3 was the driving force for this slider-crank WEC, which is connected to a motor/generator set through a gearbox. RM3 geometry was scaled down by 25 times to work within the limits of the physical motor/generator set used in the experimentation. Once the integration in a hardware-in-the-loop simulation environment was successfully completed, data on the peak-toaverage power ratio was collected for various wave conditions including regular and irregular waves. The control algorithm designed to keep the system in resonance with waves was able to maintain relatively high speed depending on the specific gear ratio and wave period. Initial results with hardware-in-theloop simulations reveal that gear ratio and crank radius have a strong impact on the peak-to-average power ratio. In addition, it was found that output power from the generator was maximized at a larger gear ratio, as the crank radius was increased.

Keywords: Wave energy converter; linear to rotary PTO; peak-to-average-power ratio; one-way continuous rotation

\section{INTRODUCTION}

A viable renewable energy alternative that has been identified in a recent White House report to meet the goals established for 2030 is marine and hydrokinetic energy [1]. Deep-water wave power resources are abundant, between $1 \mathrm{TW}$ and $10 \mathrm{TW}$ [2]. Water also has a high-power density that is 832 times greater than the air power density. The high-power density of water implies that large amounts of energy can be obtained from relatively small devices in the ocean. For example, it would require a wind turbine three times the size of a regular-sized underwater turbine to generate the same amount of power from wind than what can be generated from water [3]. This means that harvesting structures for open-ocean waves would be of a smaller size and be less invasive while producing more power than currently implemented wind turbines. However, at present, ocean wave energy is the most expensive type of water power. Forecasting and calculating the ocean energy that can be harvested is not easy because of a lack of available models of wave energy converters (WECs) [4]. In addition, ideal sinusoidal wave conditions rarely exist in real oceans and real wave conditions are highly irregular, which in turn pose significant challenges of control and design for harvesting a substantial portion of this energy. Therefore, developing new WEC models that can efficiently harness wave energy is critical for the future of the utilization of ocean wave energy in our renewable generation mix.

A research study conducted in 2011 showed that the ratio between peak power and average power absorbed by a WEC can be as high as 58 when applying well-known complex conjugate control techniques with irregular waves [5]. The study also showcased a control method with power saturation provisions to reduce this ratio as well as the rating, and the cost of power electronics equipment. Even in the case presented, it required a $110-\mathrm{kW}$ saturation rating to be able to extract 16.4 $\mathrm{kW}$ of average wave power. In another recent study [6], a specific type of WEC (oscillating water column) with a highspeed valve is utilized with a nonlinear latching control technique to limit the peak-to-average power (PTAP) ratio. Both of these research studies employed very specialized power saturation or limiting methods, which are only applicable to specific WEC-power-take-off (PTO) systems. Although it is qualitatively discussed in [6], these research efforts did not really quantify the impact of system parameters, such as an inertia or gear ratio to the PTAP ratio. In addition to the power variability concern, WECs commonly use linear generators and often face various challenges that are encountered even at relatively low power levels around $10 \mathrm{~kW}$ [7].

Motivated by these challenges, the aim of the study presented in this paper is to conduct research and development (R\&D) activities to advance the models for cost-effective wave energy conversion to support some of the educational initiatives of the U.S. government [8, 9]. These WEC platformindependent models integrated with an inertia element and

${ }^{1}$ Contact author: hbkarayaka@email.wcu.edu 
control law will be specifically addressing the challenge of a large PTAP ratio, which is inherent to most WEC systems [6].

The open-source wave energy converter simulation tool (WEC-Sim) was originally developed by the collaboration of the National Renewable Energy Laboratory and Sandia National Laboratories in 2014 [10]. WEC-Sim is developed in MATLAB/Simulink and has the ability to model devices that comprise rigid bodies, PTO systems, and mooring systems. Many additional features have been added since then. The present work with its real-time hardware-in-the-loop (HIL) environment focus designs and tests a numerical model integrated to WEC-Sim that gives an indication on how system parameters along with an advanced control algorithm can potentially affect a rotational WEC's PTAP ratio.

\subsection{Hypothesis and Research Objectives}

A prominent aspect that makes commonly used horizontalaxis wind turbines cost-competitive and efficient is their ability to maintain continuous rotation at a relatively fixed speed and torque. This is primarily because of the large inertia associated with the turbine and advanced control techniques applied to power electronic converters [11]. Inspired by this fact, the hypothesis of this research is that a rotational WEC-PTO that maintains continuous rotation with a large enough inertia can achieve a reasonably low PTAP ratio. The objectives for this study are to 1) develop an advanced control algorithm that can maintain continuous rotation for at least one rotational WEC design, and 2) properly couple the system with an inertia element and collect and analyze PTAP ratio data depending on various wave conditions.

In rotational WEC applications, it is often difficult to achieve continuous one-way rotation in an economic, efficient, and robust manner. For example, a group of researchers successfully designed a mechanical motion rectifier that can be used in various energy harvesting schemes [12]. However, this mechanism would require additional cost and complexity for a WEC system in which the cost of producing electricity is already not competitive in comparison to wind or solar energy. Other one-way rotation mechanisms usually need a one-way clutch to keep the generator's shaft rotating in one direction and latching techniques in case of extreme waves, which adds to the complexity of their structures [13]. This study makes use of an advanced control methodology that ensures one-way continuous rotation at relatively high speed and efficiency. This method does not rely on the wave motion (small, large, fast, or slow) to achieve continuous rotation. To do that, the electric machine operates in the generator and the motor modes for every half cycle of a wave [13]. This way the WEC-PTO resonates with the waves. This control methodology can be applied to any oscillating WEC-PTO system that comprises a linear-to-rotary linkage. In the study presented in this paper, WEC-Sim reference model 3 (RM3) and slider-crank linear to rotary linkage is utilized to fulfill the research objectives. The integration scheme is shown in Fig. 1. The slider on the right is assumed to be attached to the float section of WEC-Sim RM3 and will be housed and move freely within the spar section of WEC-Sim RM3. The slider crankshaft, as well as gearbox and the electrical generator, are assumed to be fixed to the spar section. The orientation of the slider crank's upstroke is in the same direction with the float's upward motion with waves.

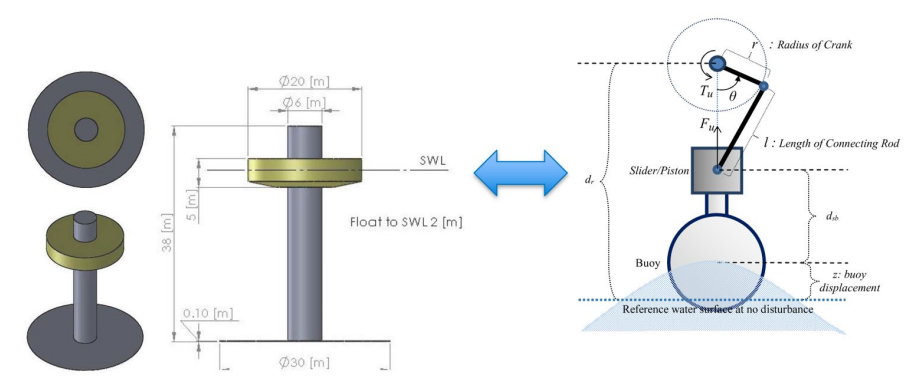

FIGURE 1: INTEGRATION OF WEC-SIM (RM3) AND THE SLIDER-CRANK WEC TO FORM A ROTATIONAL WEC-PTO.

\subsection{Methodology}

The basic scientific approach behind PTAP ratio reduction can be explained through an armature-controlled (constant field) DC machine block diagram, as shown in Fig. 1. This principle can also be generalized to vector-controlled asynchronous or synchronous $\mathrm{AC}$ machines in which torque and flux producing current components are decoupled to provide similar control advantages as in DC machines.

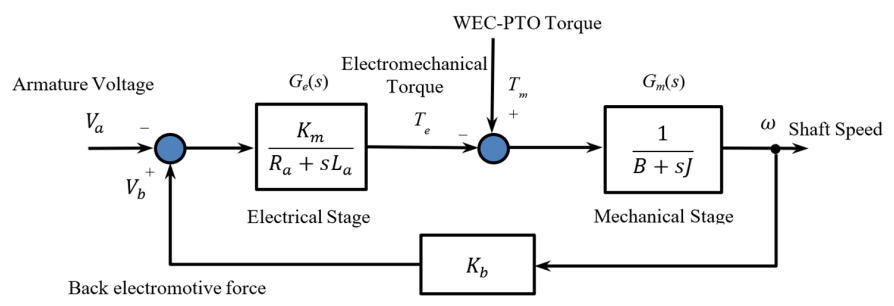

FIGURE 2: ARMATURE-CONTROLLED DC GENERATOR BLOCK DIAGRAM.

In the control framework, mechanical torque developed by WEC-PTO $T_{m}$ is treated as a torque input to the DC machine. Shaft speed, $\omega$, is the machine's output. $T_{e}$ is an electromechanical torque developed by the machine. The other symbols in Fig. 1 are $V_{b}$, back electromotive force; $V_{a}$, armature voltage; $K_{b}$, voltage constant; $K_{m}$, torque constant; $R_{a}$ and $L_{a}$, armature resistance and inductance, respectively; and $B$ and $J$, rotational viscous damping and inertia, respectively. Equations (1) - (6) show that the electrical power output from this system has a time constant that is directly proportional to the system inertia, $J$.

Assuming much smaller electrical stage time constant defined by $L_{a} / R_{a}$ than mechanical stage time constant $J / B, G_{e}(s)$ can be reduced to $K_{m} / R_{a}$. Then, the transfer function that relates $\omega$ to $T_{m}$ in the time domain is:

$$
G_{1}(s)=\frac{\omega(s)}{T_{m}(s)}=\frac{G_{m}(s)}{1+K_{b} G_{e}(s) G_{m}(s)}=\frac{\tau / J}{1+\tau s}
$$

where $s$ is the Laplace variable and the system time constant is: 


$$
\tau=\frac{R_{a} J}{\left(R_{a} B+K_{b} K_{m}\right)}
$$

The transfer function that relates $\omega$ to $V_{a}$ can be found similarly:

$$
G_{2}(s)=\frac{\omega(s)}{V_{a}(s)}=\frac{G_{e}(s) G_{m}(s)}{1+K_{b} G_{e}(s) G_{m}(s)}=\frac{\tau K_{m} /\left(J R_{a}\right)}{1+\tau s}
$$

Finally, $\omega$ output can be represented based on $V_{a}$ and $T_{m}$ inputs using the principle of superposition:

$$
\omega(s)=G_{1}(s) T_{m}(s)+G_{2}(s) V_{a}(s)
$$

The electrical power supplied by the machine is then:

$$
P_{e}(s)=V_{b}(s) I_{a}(s)=\frac{K_{b}}{K_{m}} \omega(s)\left(T_{m}(s)-\omega(s) G_{m}(s)\right)
$$

where $I_{a}(s)$ is the armature current. If $\omega(s)$ from (4) is substituted in (5) and " $(s)$ " terms are omitted for the sake of simplicity:

$$
\begin{gathered}
P_{e}=\frac{K_{b}}{K_{m}}\left\{\left(G_{1}-G_{1}^{2} / G_{m}\right) T_{m}^{2}+\left(G_{2}-2 G_{1} G_{2} / G_{m}\right) V_{a} T_{m}\right. \\
-G_{2} V_{a}^{2} \\
\left./ G_{m}\right\}
\end{gathered}
$$

It can be shown that the transfer functions in (6) that multiply $T_{m}^{2}, V_{a} T_{m}$, and $V_{a}^{2}$ terms have some low pass filter functionality characterized by the time constant, $\tau$. In this study's PTAP ratio reduction approach, electromechanical torque, $T_{e}$ (controlled by $V_{a}$ ), tracks WEC-PTO torque, $T_{m}$, to achieve continuous unidirectional rotation. When the machine's torque limit is exceeded, additional torque is smoothed by the time constant, $\tau$, which is a function of inertia and viscous damping coefficients, $J$ and $B$, respectively. However, this may not be satisfactory in some cases where the difference between these two torques is significant. Therefore, WEC-PTO torque, $T_{m}$, is modified up and down by adjusting the gear ratio and slider-crank radius based on the formulation of $T_{m}$ discussed at length in [13]. This way, fluctuations in the output power and PTAP radio can be further minimized.

\subsection{Experimental Setup and Design}

The experimental setup was designed using the WEC-Sim RM3 [13] and applying this model to a physical experiment. WEC-Sim RM3 outputs the hydrodynamic forces, which are the input into a Simulink system where an HIL simulation takes place. Fig. 3. gives a detailed visualization of the project's scope and experimental setup.

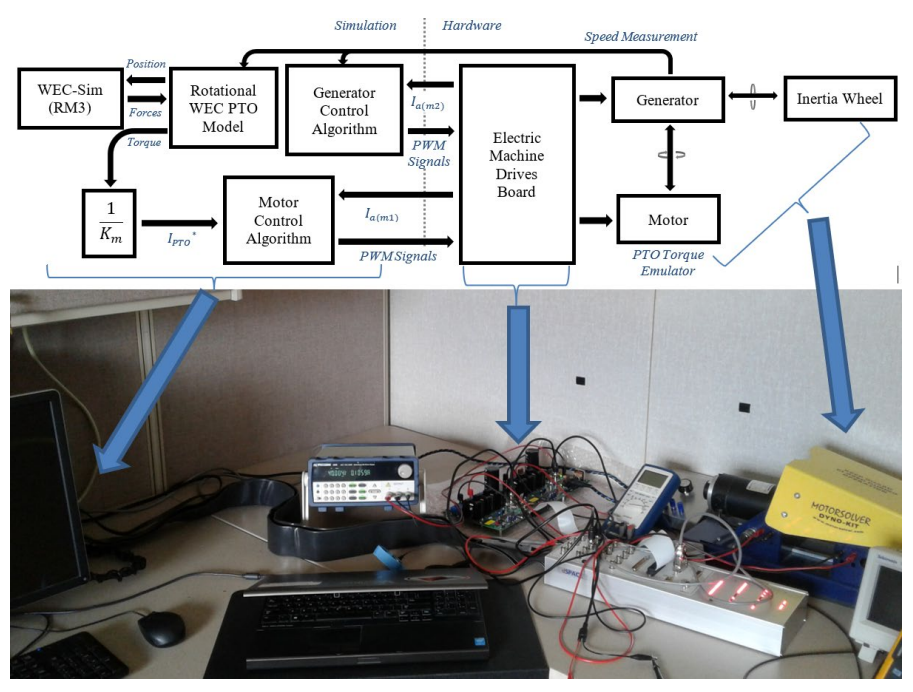

FIGURE 3: OVERVIEW OF PROJECT SCOPE VIA HARDWARE-IN-THE-LOOP SIMULATION AND EXPERIMENTAL SETUP

In Fig. $3, I_{P T O}{ }^{*}$ is the WEC-PTO torque reference for the motor controller, $I_{a(m l)}$ is the measured armature current for the motor, and $I_{a(m 2)}$ is the measured armature current for the generator. The experiment consists of two DC machines coupled together, one acting as the motor or PTO torque emulator and the other acting as the generator. The control of two separate machines is achieved using the dSPACE 1104 digital signal processor (DSP) board, which allows the full control of an electric machine drives board. The DSP control board takes measurements and sends the data to the dSPACE Control Desk software, a GUI application that displays the data and records the measurements. The slider-crank WEC-PTO model that represents the "Rotational WEC-PTO model" block was used in this project [13].

The torque developed by slider-crank WEC is divided by the motor torque constant to convert to the current reference. This reference is applied to the motor controller that controls the current into the motor, which acts like the PTO torque emulator in the system. The speed sensed from the encoder attached to the motor/generator shaft is integrated to calculate the shaft position/angle. Both shaft speed and position information are used by the slider-crank WEC-PTO model for torque calculation. The generator control algorithm takes the position information and processes through its multiple-stage control blocks. Eventually, the algorithm generates pulse-width modulated (PWM) signals for armature voltage control to make sure the generator synchronizes with the excitation force acting on WEC-Sim RM3 (a reactive control method in which the wave excitation force and WEC-PTO velocity are kept inphase). The entire simulation model (upper left half of Fig. 3) is eventually uploaded and runs from the DSP hardware board (attached to the desktop computer in the far-left side of the experimental setup).

In WEC-Sim RM3 (a two-body system), both hydrodynamic bodies (float and spar) were restricted to move in the heave direction only. This way, the excitation force that actuates the PTO can be preprocessed for the sake of simplicity. 
This excitation force is calculated by subtracting the excitation force for the float from the excitation force for the spar.

The Simulink system designed for the integration of WECSim RM3 and slider-crank models in a closed-loop HIL simulation environment is shown in Fig. 4. The WEC-Sim block represents the mechanical subsystem in Fig. 4. The electrical subsystem details are provided in Fig. 5. This system includes a PTO torque emulator, which is the violet frame in the lower-left corner. The emulator processes the PTO force input from the mechanical subsystem. This force goes through the slider-crank torque function, which produces the crankshaft torque. This torque is then divided by the DC motor's torque constant to issue the reference armature current for the PTO torque emulator, which produces PWM signals to control the DC motor through the electric machines drive board. The DC motor's shaft is directly coupled to the generator's shaft, which is controlled by the green frame in the upper right corner in Fig. 5. The reference speed for the generator's controller is issued by the control algorithm (the gray frame in the upper left corner) to keep the PTO velocity in resonance with the wave excitation forces. Measured speed on the shaft (small gray block in the middle) is integrated to calculate the displacement and velocity for the slider crank, which are issued as outputs to the mechanical subsystem (WEC-Sim RM3). There is a total of three proportional-integral (PI) controllers employed in the electrical subsystem. One PI controller is designed to control the armature current for the PTO torque emulator and the other two PI controllers that operate in a nested loop topology are designed to control the armature current and shaft speed for the generator. On the other hand, the resonance control algorithm (represented by the gray frame) is a rule-based phase-lock control mechanism discussed in detail in [13]. In short, this control process detects zero crossings and half-periods through pre-processed data arrays and "Period Calc1" block in Fig. 5 under the assumption of perfect knowledge of the wave excitation force. After that, the angular variation for the future half cycle is predicted by a linear interpolation method in "Angle Reference Gen" block in Fig. 5. This is the reference

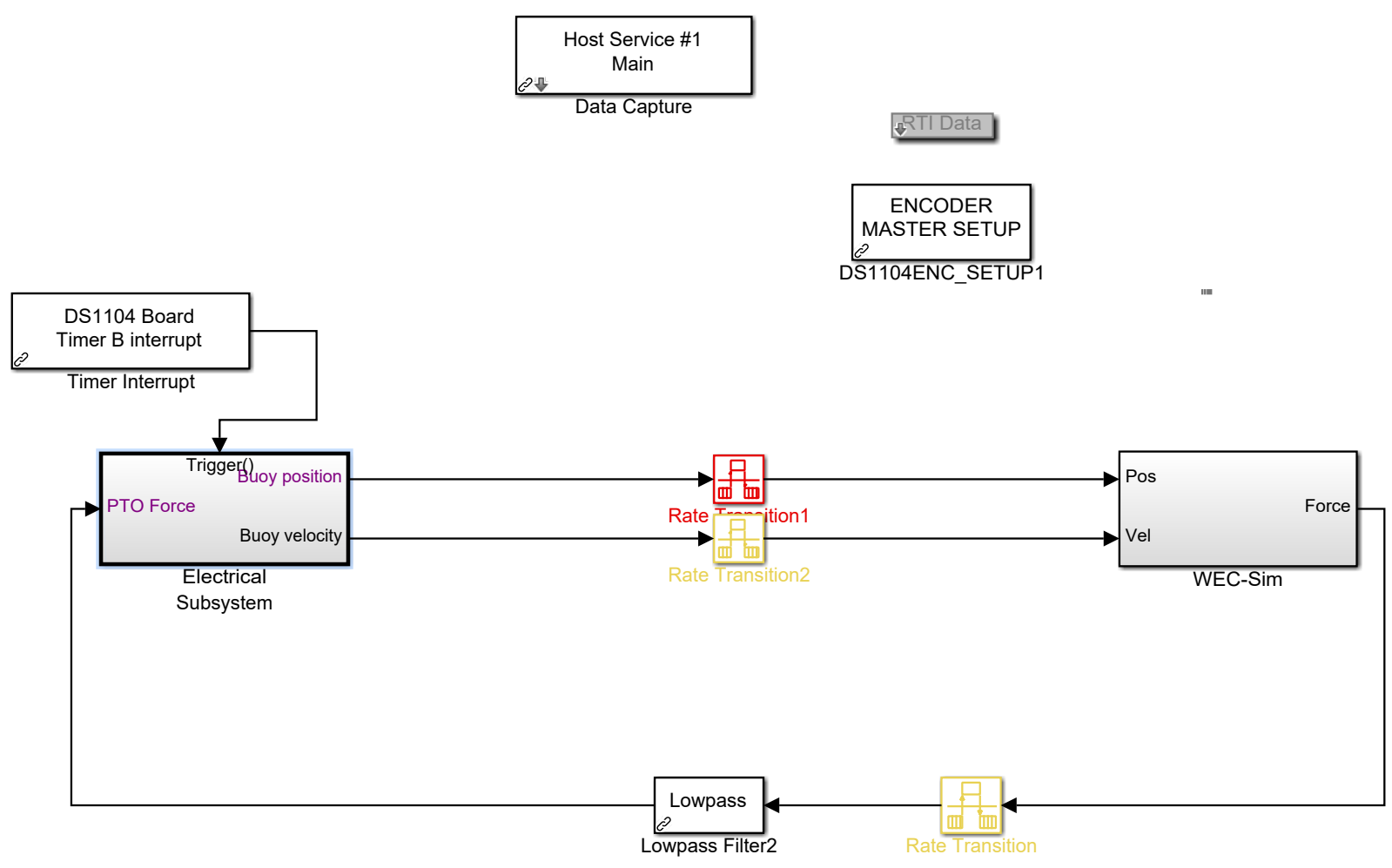

FIGURE 4: MAIN SIMULINK SYSTEM DESIGNED FOR CLOSED-LOOP REAL-TIME CONTROL 


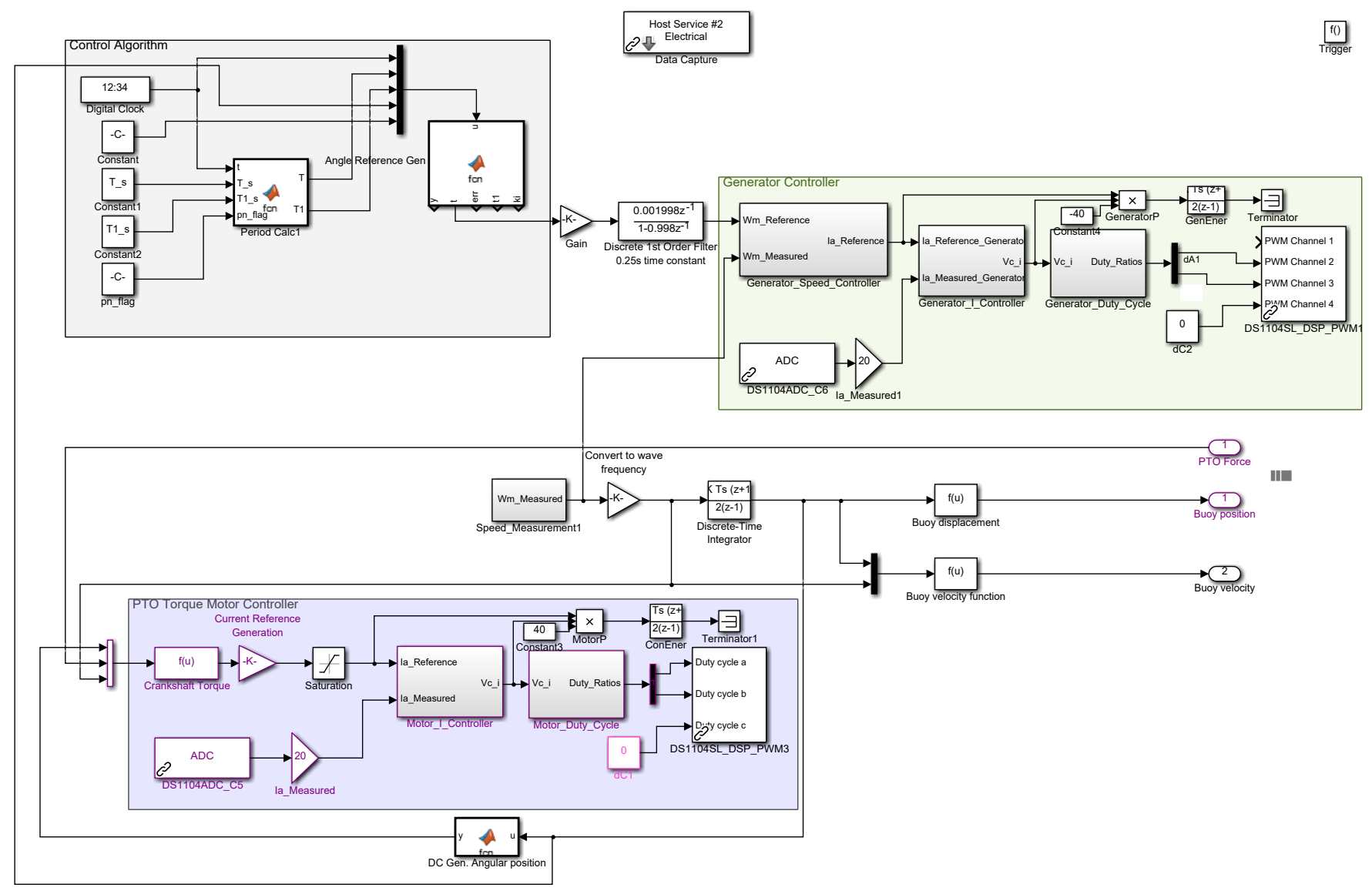

FIGURE 5: SIMULINK ELECTRICAL SUBSYSTEM DETAILS

angle that is compared against the measured shaft angle to evaluate the control error. To maintain phase-lock/resonance condition, the angle error is later processed by a control algorithm to generate a speed reference for the generator's controller. The reference needs to be issued before the next half cycle begins for proper angle tracking. This reference is finally low-pass filtered to avoid sharp transients in the generator dynamics. In the simulation system, a gearbox model was placed between the slider crank and the motor/generator shafts.

In this study, perfect knowledge of future half-period knowledge of the wave excitation force was assumed. An adaptive autoregressive filter prediction algorithm for the excitation force was developed and analyzed for regular and irregular wave conditions in [14]. The prediction performance of this filter was also analyzed in a slider crank WEC simulation scheme in [15]. The results with irregular wave peak periods of 6 through $10 \mathrm{~s}$ showed that captured wave power was reduced approximately $4 \%$ in comparison to the perfect knowledge of wave excitation force case. Testing with regular wave periods resulted in negligible reduction in captured power.

In terms of real-time simulation software design, the following challenges had to be overcome:

- The sampling time for the electrical subsystem (anything other than the WEC-Sim block in Fig. 4) has to be at least $0.5 \mathrm{~ms}$ to ensure appropriate current and torque control.
However, WEC-Sim uses a continuous-time simulation solver that picks up the fastest sampling time in the Simulink framework. If that happens, every subsystem was supposed to run at a $0.5-\mathrm{ms}$ sampling time, which caused task overrun errors during the real-time build and upload cycles. To overcome this challenge, the electrical subsystem was discretized and packaged to be triggered by the digital signal processor board's hardware-timer interrupt at $0.5-\mathrm{ms}$ intervals. This way, the electrical subsystem was scheduled as a higher priority task than the mechanical subsystem, which is not necessarily run at fast sampling speeds.

- WEC-Sim RM3 PTO was normally supposed to be actuated by motion, which is the position information for the slidercrank WEC. This actuation method required position, velocity, and acceleration and was extremely sensitive to any noise because of the derivation process. The actuation method was changed to a much more stable force input framework, which was driven by a proportional-integralderivative (PID) controller for a specific position setpoint. Tuning of this controller was done manually (P parameter first for a minimal error, then D parameter to avoid jitter, and finally I parameter for eliminating the steady-state error).

- Motor faults in the electronic controller boards were causing continuous disruption during testing. The solution was later 
discovered through a data sheet (for metal oxide semiconductor field effect transistor (MOSFET) gate drive circuitry IR2133) provided by the manufacturer. Accordingly, the potentiometers for the motor and the generator drive circuitry were adjusted to meet expected current limits based on the specifications.

Once these challenges were overcome, the following testing methods and constraints were applied to collect the real-time data from the hardware-in-the-loop simulation environment:

- WEC-Sim RM3 was scaled down for testing by Froude scaling law [16] to comply with the hardware components ratings. The original geometry was decided to be scaled down by 25 times $(F r=25)$ after some initial analysis. Accordingly, the hydrodynamic forces are reduced by $\mathrm{Fr}^{3}=$ 15625, wave heights are reduced by $F r=25$, and wave periods as well as simulation time are reduced by $\sqrt{F r}=5$.

- Regular waves to be tested were i) height $(H)=2 \mathrm{~m}$ for periods $(T)=5,10$ and $15 \mathrm{~s}$, ii) height $(H)=1 \mathrm{~m}$, periods $(T)$ $=5,10$ and $15 \mathrm{~s}$.

- Irregular waves to be tested (using the Brettschneider spectrum) were significant wave height $\left(H_{s}\right)=1.5 \mathrm{~m}$, and peak period $\left(T_{p}\right)=10$ and $15 \mathrm{~s}$. These irregular waves were formed by the composition of 70 regular waves.

- $\quad$ The test duration was $80 \mathrm{~s}$ (original test duration of 400 was divided by the time scaling factor explained earlier) for regular waves. The test duration was $320 \mathrm{~s}$ for irregular waves to cover a broad range of operations.

- The gear ratio was varied between 20 to 80, with 10 steps, and data were collected, as long as the motor overcurrent fault did not occur.

- $\quad$ The slider-crank radius to connecting arm length ratio $(l / r$ in reference to Fig. 1) was fixed at 0.5 throughout the testing. Slider-crank radius (full scale) values of $1.25 \mathrm{~m}, 2 \mathrm{~m}$, and $2.5 \mathrm{~m}$ were used during testing.

- WEC-Sim RM3 bodies (float and spar) were restricted to move in heave direction only.

- The power electronic converters that feed the motor or the generator are capable of operating these machines in four quadrants. Each converter consists of six MOSFETs, of which only four were utilized for DC-DC bidirectional power transfer mode. The main DC bus is configured for 40 $\mathrm{V}$ through an external DC power supply.

\subsection{Experimental Results}

The WEC-PTO design with HIL simulations successfully resulted in unidirectional continuous rotation, as shown in Fig. 6 for both regular and irregular waves. It is important to note that the time scale is approximately four times larger in the case of the irregular wave, so the ramp rates in speed are more benign than what is perceived. In addition, output voltage fluctuation of $\pm 1 \%$ within the rated value of $40 \mathrm{~V}$ (DC Bus) was achieved. The maximum fluctuation observed, which corresponded to peak power durations, was about $30 \mathrm{mV}$.
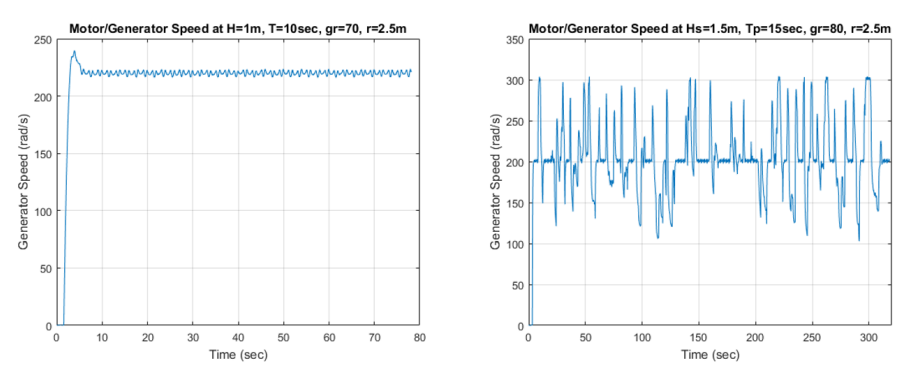

FIGURE 6: MOTOR/GENERATOR SHAFT SPEED FOR A REGULAR WAVE (LEFT) AND AN IRREGULAR WAVE (RIGHT) CASE

Generated electrical power's PTAP ratio results for regular and irregular waves are summarized in Table 1 for a slider-crank radius of $r=2.5 \mathrm{~m}$. Mean values of generated electrical power for regular and irregular waves are summarized in Table 2 for a slider-crank radius of $r=2.5 \mathrm{~m}$. The drive torque for a slider crank linkage is directly proportional to the crank radius under the assumption of fixed $l / r$ ratio. Therefore, the shaft power for a given speed would increase proportionally with increasing radius. This was also observed during the tests. For a given gear ratio, larger radius yielded larger power and smaller PTAP ratio. The results for the gear ratio of 50 are listed in Table 3.

In terms of the PTAP ratio, the gear ratio of 50 and $r=2.5$ $\mathrm{m}$ was the overall best. In terms of average extracted power, the gear ratio of 60 and $r=2.5 \mathrm{~m}$ was the overall best. The gear ratio of 60 should be selected because the PTAP ratio difference between 50 and 60 was negligible.

The rationale for some of the data labeled by "NA" can be explained as follows. In the case of $T=5 \mathrm{~s}$ with regular waves, testing with a gear ratio of 70 or above resulted in overcurrent faults. Therefore, the results were not collected for the ratio of 70 or for the ratio of 80, as shown in Tables 1 and 2. In addition, the gear ratio of 70 or above would not result in appreciable values of PTAP ratio and output power because the PTAP ratio was increasing and average power was decreasing by increased values of gear ratio. In the case of irregular waves, the system was unable to extract positive power at $H_{s}=1.5 \mathrm{~m}$ and $T_{p}=10 \mathrm{~s}$, because incoming mechanical power through the torque emulator was not high enough to overcome losses in the energy conversion chain. Therefore, the PTAP ratio was not calculated for this data set. However, the system was able to extract positive power at $H_{s}=1.5 \mathrm{~m}$ and $T_{p}=15 \mathrm{~s}$, as shown in Table 2. Similar cases of not being able to extract power did occur with regular waves as well. For example, the crank radius of $1.25 \mathrm{~m}$, regardless of the gear ratio, did not result in any positive power at $H=1 \mathrm{~m}$ and $T=5 \mathrm{~s}$ or $T=10 \mathrm{~s}$ as shown by "NA" in Table 3.

An observation of the PTAP ratio was also conducted on the motor side (torque emulator). The motor's incoming power needs to be larger than the generator's output power by a certain offset to ensure positive efficiencies. In the case of regular waves $(r=2.5 \mathrm{~m})$, the incoming slider-crank power draw was varying generally between 40 and $80 \mathrm{~W}$. The PTAP ratio for this power was always smaller than the electrical power output and varying generally between 2 and 4. In the case of irregular waves (again $r=2.5 \mathrm{~m})$, the incoming slider-crank power was varying 
generally between 30 and $50 \mathrm{~W}$. The PTAP ratio for this power was varying generally between 3 and 10 . These results support the electrical power vs. PTAP ratio trends in Tables 1 and 2 (i.e., the higher the electrical power (absorbed or generated), the lower the PTAP ratio). This fact can be explained by a sine wave biased with a certain fixed positive value. As this value increases, the PTAP ratio would decrease. The relationship between the characteristics of power through the torque emulator and the generator are shown in Figs. 7 and 8 for a specific case of a regular wave, gear ratio, and crank radius.

One final observation in terms of PTAP ratio reduction was in the control law. If the voltage ramp rates to the torque emulator motor were kept in a certain range, then the PTAP ratio reduces. However, this method has a limit. Beyond a certain limit, the controller has a disadvantage of not catching up with the fast torque/current transients in a timely manner. Eventually, this may result in overcurrent faults on the drives board.

TABLE 1. PTAP RATIO FOR THE GENERATOR AND SLIDERCRANK RADIUS OF $2.5 \mathrm{M}$

\begin{tabular}{|c|c|c|c|c|c|c|c|c|}
\hline \multirow{2}{*}{$\begin{array}{l}\text { Gear } \\
\text { Ratio }\end{array}$} & \multicolumn{3}{|c|}{ Regular Waves $H=1 \mathrm{~m}$} & \multicolumn{3}{|c|}{ Regular Waves $H=2 \mathrm{~m}$} & \multicolumn{2}{|c|}{$\begin{array}{c}\text { Irregular Wave } \\
\quad H_{s}=1.5 \mathrm{~m}\end{array}$} \\
\hline & $T=5 \mathrm{~s}$ & $T=10 \mathrm{~s}$ & $T=15 \mathrm{~s}$ & $T=5 \mathrm{~s}$ & $T=10 \mathrm{~s}$ & $T=15 \mathrm{~s}$ & $T_{p}=10 \mathrm{~s}$ & $T_{p}=15 \mathrm{~s}$ \\
\hline 40 & 10.6 & 57.0 & 2.31 & 8.63 & 15.8 & 2.34 & NA & 407 \\
\hline 50 & 15.3 & 25.4 & 2.38 & 11.5 & 8.71 & 2.34 & NA & 35.4 \\
\hline 60 & 32.8 & 17.5 & 2.48 & 13.4 & 7.88 & 2.42 & NA & 25.2 \\
\hline 70 & NA & 20.5 & 2.66 & NA & 7.82 & 2.61 & NA & 23.6 \\
\hline 80 & NA & 45.4 & 3.15 & NA & 9.87 & 2.90 & NA & 21.8 \\
\hline
\end{tabular}

TABLE 2. EXTRACTED AVERAGE ELECTRICAL POWER (WATTS) FROM THE GENERATOR FOR SLIDER-CRANK RADIUS OF $2.5 \mathrm{M}$

\begin{tabular}{|c|c|c|c|c|c|c|c|c|}
\hline \multirow{2}{*}{$\begin{array}{c}\text { Gear } \\
\text { Ratio }\end{array}$} & \multicolumn{3}{|c|}{ Regular Waves $\boldsymbol{H = 1} \mathbf{~ m}$} & \multicolumn{3}{|c|}{ Regular Waves $\boldsymbol{H = 2} \mathbf{~ m}$} & \multicolumn{2}{|c|}{$\begin{array}{c}\text { Irregular Wave } \\
\boldsymbol{H}_{s}=1.5 \\
\mathbf{~ m}\end{array}$} \\
\cline { 2 - 10 } & $T=5 \mathrm{~s}$ & $T=10 \mathrm{~s}$ & $T=15 \mathrm{~s}$ & $T=5 \mathrm{~s}$ & $T=10 \mathrm{~s}$ & $T=15 \mathrm{~s}$ & $T_{p}=10 \mathrm{~s}$ & $T_{p}=15 \mathrm{~s}$ \\
\hline $\mathbf{4 0}$ & 14.9 & 2.25 & 13.4 & 18.8 & 7.52 & 14.2 & -14.0 & 0.41 \\
\hline $\mathbf{5 0}$ & 14.7 & 5.02 & 19.3 & 17.0 & 12.9 & 20.1 & -10.7 & 5.57 \\
\hline $\mathbf{6 0}$ & 5.68 & 7.10 & 23.7 & 13.6 & 14.3 & 24.6 & -9.60 & 8.77 \\
\hline $\mathbf{7 0}$ & NA & 6.23 & 26.3 & NA & 15.2 & 27.3 & -10.3 & 10.6 \\
\hline $\mathbf{8 0}$ & NA & 2.92 & 27.5 & NA & 13.6 & 29.2 & -13.2 & 12.1 \\
\hline
\end{tabular}

TABLE 3. PTAP RATIO AS A FUNCTION OF CRANK RADIUS FOR THE GENERATOR AND GEAR RATIO OF 50

\begin{tabular}{|c|c|c|c|c|c|c|c|c|}
\hline \multirow{2}{*}{$\begin{array}{c}\text { Crank } \\
\text { Radius } \\
\text { (m) }\end{array}$} & \multicolumn{3}{|c|}{ Regular Waves $H=1 \mathrm{~m}$} & \multicolumn{3}{|c|}{ Regular Waves $H=2 \mathrm{~m}$} & \multicolumn{2}{|c|}{$\begin{array}{c}\text { Irregular Wave } \\
H_{s}=1.5 \mathrm{~m}\end{array}$} \\
\hline & $T=5 \mathrm{~s}$ & $T=10 \mathrm{~s}$ & $T=15 \mathrm{~s}$ & $T=5 \mathrm{~s}$ & $T=10 \mathrm{~s}$ & $T=15 \mathrm{~s}$ & $T_{p}=10 \mathrm{~s}$ & $T_{p}=15 \mathrm{~s}$ \\
\hline 1.25 & NA & NA & 19.0 & NA & 123 & 24.3 & NA & NA \\
\hline 2 & NA & 52.0 & 3.12 & 37.4 & 8.71 & 3.06 & 25.0 & NA \\
\hline 2.5 & 15.3 & 25.4 & 2.38 & 11.5 & 7.73 & 2.34 & 20.4 & 35.4 \\
\hline
\end{tabular}

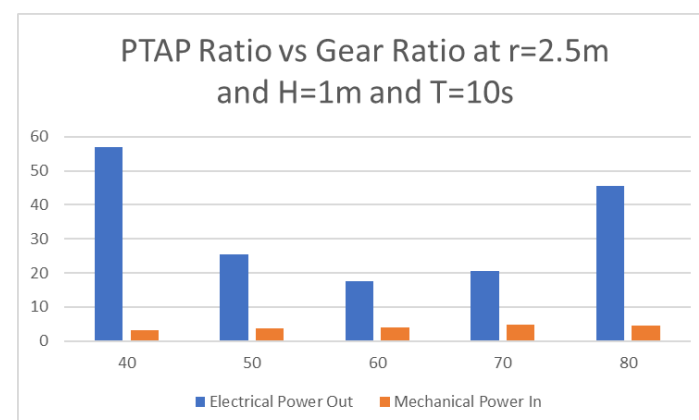

FIGURE 7: PTAP RATIO FOR THE GENERATOR (BLUE) AND THE TORQUE EMULATOR (ORANGE)

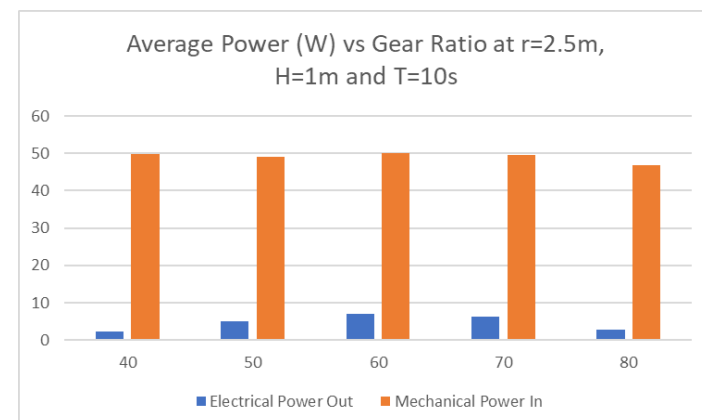

FIGURE 8: AVERAGE POWER FOR THE GENERATOR (BLUE) AND THE TORQUE EMULATOR (ORANGE)

\section{CONCLUSIONS}

The hypothesis was justified, and unidirectional continuous rotation was achieved for a wide range of regular and irregular waves (although inertia was kept constant at its default value). As the crank radius was increased, the maximum average power was achieved at a larger gear ratio. The best overall results for both the PTAP ratio and average power were achieved with a crank radius of $2.5 \mathrm{~m}$. As the wave period reduced, maximum power was achieved at a smaller gear ratio. The best overall results for both the PTAP ratio and average power were achieved with a gear ratio of 60 . The electrical output power extracted at the generator was smaller than incoming power at the torque emulator, with efficiencies varying between 40 and $60 \%$ per machine. The PTAP ratio can be further reduced for specific gear ratios and crank radius settings. Incoming mechanical power should be increased to avoid the offsets because of the standby 
power used to maintain speed and overcome losses. A minimum of $\sim 40 \mathrm{~W}$ at the torque emulator is required to ensure positive electrical power at the generator.

The important future steps in this study can be listed as follows. Because the default inertia of the coupled motor/generator system was assumed throughout the project, inertia testing should be conducted thoroughly for multiple different configurations to investigate the impact on the PTAP ratio. Scaling the original RM3 geometry by Froude's law needs to be reevaluated to improve full-scale electrical power and PTAP ratio projections. Another rotational WEC-PTO instead of RM3 or slider crank should be evaluated for performance. In addition, the impact of phase-lock condition (between generator and wave forces) on PTAP ratio and power output should be investigated. Finally, wave excitation forces for the 3 degreesof-freedom WEC-Sim RM3 should be evaluated during runtime for more realistic simulations.

\section{ACKNOWLEDGEMENTS}

This work was supported [in part] by the U.S. Department of Energy, Office of Science, Office of Workforce Development for Teachers and Scientists under the Visiting Faculty Program. Task Number Visiting Faculty Program ERPG. 10213.04.01.01. The views expressed in the article do not necessarily represent the views of the DOE or the U.S. Government. The U.S. Government retains and the publisher, by accepting the article for publication, acknowledges that the U.S. Government retains a nonexclusive, paid-up, irrevocable, worldwide license to publish or reproduce the published form of this work or allow others to do so, for U.S. Government purposes.

\section{REFERENCES}

[1]. The White House, "Accelerating the transition to clean energy," [Online]. Available: https:/www.whitehouse.gov/sites/default/files/accelerati ng_clean_energy.pdf

[2]. Engineering Committee on Oceanic Resources Working Group on Wave Energy Conversion (2003), John Brooke, ed., Wave Energy Conversion, Elsevier, pp. 7, ISBN 0080442129.

[3]. Cruz J., Gunnar M., Barstow S., Mollison D. (2008), Joao Cruz, ed., Green Energy and Technology, Ocean Wave Energy, Springer Science+Business Media, pp. 93, ISBN 978-3-540-74894-6.

[4]. V. S. Neary, M. Previsic, R. A. Jepsen, M. J. Lawson, YH. Yu, A. E. Copping, A. A. Fontaine, K. C. Hallett, D. K. Murray, "Methodology for design and economic analysis of Marine Energy Conversion (MEC) technologies," Sandia National Laboratories, Albuquerque, NM, Rep. SAND-2014-9040, 2014.

[5]. E. Tedeschi, M. Carraro, M. Molinas, and P. Mattavelli, "Effect of control strategies and power take-off efficiency on the power capture from sea waves," IEEE Trans. Energy Convers., vol. 26, no. 4, pp. 1088-1098, Dec.
2011

[6]. J. C. C. Henriques, L. M. C. Gato, J. M. Lemos, R. P. F. Gomes, A. F. O. Falcao, "Peak-power control of a gridintegrated oscillating water column wave energy converter," Elsevier, Energy, vol. 109, pp. 378-390, Aug. 2016.

[7]. Ken Rhinefrank, Alphonse Schacher, Joseph Prudell, Ted K. A. Brekken, Chad Stillinger, John Z. Yen, Steven G. Ernst, Annette von Jouanne, Ean Amon, Robert Paasch, Adam Brown, and Alex Yokochi "Comparison of DirectDrive Power Takeoff Systems for Ocean Wave Energy Applications," IEEE Journal of Oceanic Engineering, vol. 37, no. 1, pp. 35-44, January 2012.

[8]. U. S. Energy Information Administration, "Electricity Data Browser," [Online]. Available: http://www.eia.gov/electricity/data/browser.

[9]. The White House, "FACT SHEET: President Obama Announces New Actions to Bring Renewable Energy and Energy Efficiency to Households across the Country," [Online]. Available: https://www.whitehouse.gov/thepress-office/2015/08/24/fact-sheet-president-obamaannounces-new-actions-bring-renewable-energy.

[10]. WEC-Sim. https://wec-sim.github.io/WEC-Sim/

[11]. L. Ran, J. R. Bumby, P. J. Tavner, "Use of Turbine Inertia for Power Smoothing of Wind Turbines with a DFIG," IEEE 11th International Conference on Harmonics and Quality of Power, 2004.

[12]. Z. Li, L. Zuo, J. Kuang, G. Luhrs, Energy-harvesting shock absorber with a mechanical motion rectifier, Smart Materials and Structures, vol. 22, no. 2, 2012.

[13]. Sang, Y., Karayaka, H., Yan, Y., Zhang, J., Bogucki, D., Yu, Y.-H., "A Rule-Based Phase Control Methodology for a Slider-Crank Wave Energy Converter Power Take-Off System," International Journal of Marine Energy, vol. 19, September 2017, pp.124-144.

[14]. Khan, M. R. H., Karayaka, H. B., Yan, Y., Tay, P. C., Yu, Y.-H., "Wave Excitation Force Prediction Methodology Based on Autoregressive Filters for Real Time Control," IEEE Green Technology Conference, 2019.

[15]. Khan, M. R. H., Karayaka, H. B., Yan, Y., Tay, P. C., Yu, Y.-H., "Slider Crank WEC Performance Analysis with Adaptive Autoregressive Filtering," IEEE SoutheastCon, 2019.

[16]. https://en.wikipedia.org/wiki/Froude_number, accessed 08/06/2019. 